\title{
Correction to: Factors affecting the discharge of patients from hospital with seasonal influenza-the role of the Rapid Influenza testing in hospital discharges
}

\author{
Ruchir Chavada $^{1} \cdot$ Liam Clifford $^{2} \cdot$ Owen Weisback $^{2}$ \\ Published online: 25 November 2020 \\ (C) Springer-Verlag GmbH Germany, part of Springer Nature 2020
}

\section{Correction to: European Journal of Clinical Microbiology \& Infectious Diseases https://doi.org/10.1007/s10096-019-03752-3}

In the originally published article, the first names and last names of authors were presented in the wrong order. The names Chavada Ruchir, Clifford Liam, and Weisback Owen should be presented as Ruchir Chavada, Liam Clifford, and Owen Weisback. These are now correctly presented above. The original article has been corrected.

Publisher's note Springer Nature remains neutral with regard to jurisdictional claims in published maps and institutional affiliations.

The online version of the original article can be found at https://doi.org/ 10.1007/s10096-019-03752-3

Ruchir Chavada

ruchirchavda@gmail.com

1 Department of Microbiology and Infectious Diseases, NSW Health Pathology-Central Coast, Gosford, Gosford, NSW, Australia

2 Department of Medicine, Wyong Hospital/Gosford Hospitals, Gosford, NSW, Australia 